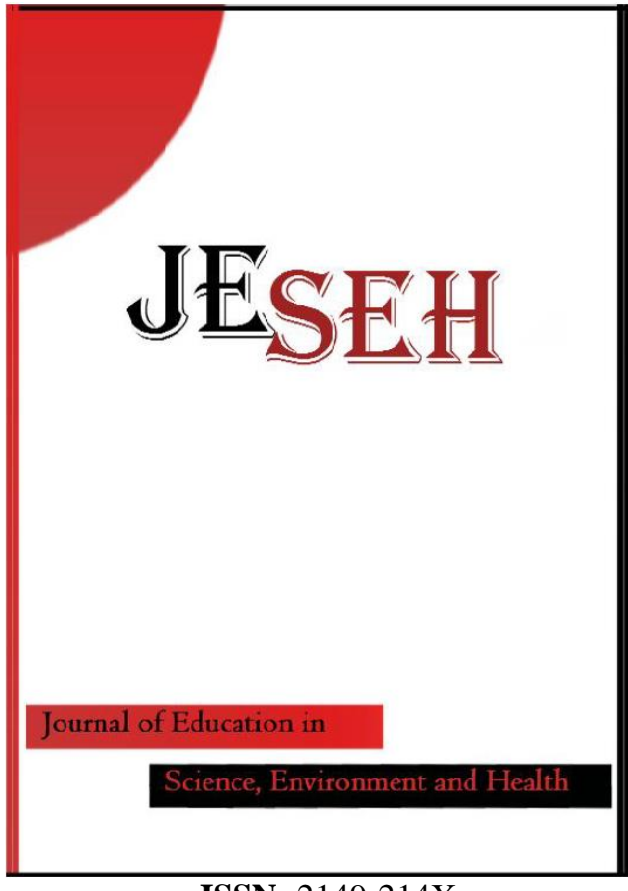

ISSN: $2149-214 \mathrm{X}$

\section{Journal of Education in Science,} Environment and Health

\section{www.jeseh.net}

\section{Cognitive Load in Multimedia Learning:} An Example from Teaching about Lenses

\author{
Dževdeta Dervić ${ }^{1}$, Nermin Đapo ${ }^{2}$, Vanes Mešić ${ }^{2}$, Ratko \\ Đokić ${ }^{2}$ \\ ${ }^{1}$ Second Gymnasium Sarajevo \\ ${ }^{2}$ University of Sarajevo
}

To cite this article:

Dervić, D., Đapo. N., Mešić, V. \& Đokić, R. (2019). Cognitive load in multimedia learning: An example from teaching about lenses. Journal of Education in Science, Environment and Health (JESEH), 5(1), 102-118. DOI:10.21891/jeseh.481698

This article may be used for research, teaching, and private study purposes.

Any substantial or systematic reproduction, redistribution, reselling, loan, sub-licensing, systematic supply, or distribution in any form to anyone is expressly forbidden.

Authors alone are responsible for the contents of their articles. The journal owns the copyright of the articles.

The publisher shall not be liable for any loss, actions, claims, proceedings, demand, or costs or damages whatsoever or howsoever caused arising directly or indirectly in connection with or arising out of the use of the research material. 


\title{
Cognitive Load in Multimedia Learning: An Example from Teaching about Lenses
}

\author{
Dževdeta Dervić, Nermin Đapo, Vanes Mešić, Ratko Đokić
}

\begin{tabular}{ll}
\hline Article Info & Abstract \\
\cline { 1 - 1 } $\begin{array}{l}\text { Article History } \\
\text { Received: }\end{array}$ 09 August 2018 & $\begin{array}{l}\text { Animations are widely used in today's science classrooms. Therefore it is very } \\
\text { important to explore under which conditions animations are most effective. In } \\
\text { earlier studies it has been generally shown that the effectiveness of instruction } \\
\text { largely depends on management of cognitive load. The aim of the present study } \\
\text { was to compare the effect of Physlet animations, printed sequences of selected } \\
\text { animation frames and traditionally presented static pictures on understanding } \\
\text { about lenses and levels of cognitive load. According to the results of a quasi- } \\
\text { experiment that included forty nine high-school students, Physlet-based teaching } \\
\text { generally leads to higher germane load and consequently to more effective } \\
\text { 11 November 2018 }\end{array}$ \\
$\begin{array}{l}\text { Keywords } \\
\text { learning than the traditional approach. Particularly high levels of germane load } \\
\text { have been found for Physlet-based problems. These findings can be accounted } \\
\text { for by the interactivity feature of Physlets. }\end{array}$ \\
$\begin{array}{l}\text { Instructional materials } \\
\text { Physlets } \\
\text { Cognitive load theory }\end{array}$
\end{tabular}

\section{Introduction}

The use of interactive multimedia learning environments has increased significantly in the last decade (FuiTheng \& Mai, 2014). Interactive multimedia learning environments are believed to facilitate learner-engaged learning which is expected to lead to deeper cognitive processes and result in active construction of new knowledge (Kalyuga, 2008). According to Spector, Christensen, Sioutine, \& McCormack (2001) it is exactly the interactivity feature of technology-enhanced learning environments which provides many opportunities for active cognitive engagement, reflection and feedback. However, the results of comparative studies about the impact of static and dynamic media on students' learning are mixed (Mešić, Dervić, Gazibegović-Busuladžić, Salibašić, \& Erceg, 2015). Researchers are still trying to understand under which conditions and why interactive animations can enhance comprehension and learning more than static pictures (Lowe \& Schnotz, 2008; Kühl, Navratil, \& Münzer, 2018; Sudatha, Degeng, \& Kamdi, 2018; Tversky, Morrison, \& Betrancourt, 2002).

A valuable theoretical framework for understanding the effects of interactive animation on learning outcomes can be found in the Cognitive load theory (see Sweller, Ayers, \& Kalyuga, 2011). According to Kalyuga (2008), dynamic interactive animations can help us to reduce the unnecessary load that is caused by inadequate instruction design or complexity of tasks, as well as to promote cognitive processes that are essential for learning. In order for the animations to facilitate learning, it is also important that their design takes into account the nature of learning of the corresponding subject matter (Rapp \& Curby, 2008). An example of interactive animations whose design was inspired by findings from research on students' learning in physics are the Physlets (Christian \& Belloni, 2001). Physlets are simple Java applets which cover most topics typically taught in introductory physics courses at the university level (Christian \& Belloni, 2013). According to Krusberg (2007) Physlets are an extremely practical and flexible educational technology whose properties make them an invaluable tool in physics education.

However, empirically grounded evidence regarding the efficacy of Physlets-based teaching is rare. As a matter of fact, there were only a few studies about this topic (e.g., Mešić, Dervić, Gazibegović-Busuladžić, Salibašić, \& Erceg, 2015; Ulen, Čagran, Slavinec, \& Gerlič, 2014; Ulen, Gerlič Slavinec, \& Repnik, 2017) and the authors of this article know of only one study (Lee, Nicoll, \& Brooks) that systematically explored the efficacy of Physletbased teaching from the perspective of Cognitive load theory. In the study by Lee, Nicoll and Brooks (2004) cognitive load has been applied for explaining why an worked example approach to using Physlets is more effective than an inquiry approach to using Physlets. However, they did not attempt to measure students' cognitive load and therefore could not establish precise relationships between cognitive load and type of learning materials. Our study was conducted with the aim of comparing effects of Physlets, printed sequences of 
static pictures generated from Physlets and traditionally presented static pictures on learning outcomes and cognitive load within the context of teaching about lenses.

\section{Background}

\section{Cognitive Load Theory}

The architecture of human cognition consists of an effectively unlimited long-term memory (LTM), which interacts with working memory (WM) that is very limited in both capacity and duration. According to Baddeley's (1992) WM model auditory information are processed in the "phonological loop" and visual information are processed in the "visual-spatial sketchpad". Any conscious cognitive activity requires working memory capacity. The basic assertion of CLT is that instructional design needs to take into account the limitations of working memory in order to prevent an overload of working memory capacity and hence a deterioration of learning (Sweller, 2005). According to Van Merriënboer \& Kirschner (2007), learning occurs if information is successfully processed in WM, which can lead to schema construction (creation of a new schemata), schema assimilation (incorporation of the new elements of information into existing schemas), schema elaboration (incorporation of elements consisting of lower level schemas into higher level schemas, resulting in more complex schemas) and schema accommodation (adaptation of existing schema based upon incongruous or inconsistent new information). According to CLT teaching material can induce three types of cognitive load in working memory. The first type of cognitive load, intrinsic cognitive load, is caused by the complexity of the information to be learned or problem to be solved. It depends on the number and interactivity of elements (symbols, concepts, procedures and rules) which simultaneously need to be processed in the working memory (Sweller, 1994). For example, memorizing individual foreign words is characterized by low element interactivity, while building sentences (i.e., combining multiple words) in a foreign language is an example of high element interactivity. The intrinsic load is defined in relation to the level of expertise of a learner (Sweller, Van Merriënboer, \& Paas, 1998).

The second type of cognitive load, extraneous cognitive load, can be induced by an inappropriate presentation of the learning material as well as by requiring the students to perform activities that are irrelevant to learning. Generally, it is induced by all the unnecessary cognitive activities that do not contribute to schema construction and automatization (Sweller, 2005). For example, integration of information from spatially separate sources of information could increase extraneous cognitive load because information from one source needs to be maintained in working memory in order to integrate it with the information from the other source (Ayres \& Sweller, 2005). Finally, the type of cognitive load that results from active schema construction processes, which promote learning, is germane load (Paas \& Van Merriënboer, 1994). Actually, germane load is related to working memory resources devoted to the load imposed by intrinsic nature of the material (Sweller, 2005).

In learning settings with a high intrinsic cognitive load, reduction of extraneous cognitive load frees working memory capacity which can be used for relevant learning processes. However, if the intrinsic load is low learning can be successful despite a high extraneous load. For learning to be effective, the total amount of cognitive load associated with an instructional design should not exceed the available WM processing capacity (Paas, Tuovinen, Tabbers, \& Van Gerven, 2003; Sweller et al, 1998; Van Merriënboer \& Sweller, 2005). In a nutshell, when managing the total cognitive load to facilitate learning, extraneous load must be reduced, intrinsic load must be adjusted and germane load must be fostered (Paas, Renkl, \& Sweller, 2003, 2004; Van Merriënboer, Kester, \& Paas, 2006).

\section{Cognitive Load in Multimedia Learning Environments}

Multimedia can be defined as an environment that offers learners access to information in a variety of formats, such as text, still images, animations, video, and audio presentations. The design of multimedia should be consistent with the assumptions put forth by CLT according to which working memory consists of two independent systems for processing verbal and audio information (Baddeley, 1992). Considering that each system has a limited capacity to process information, multimedia can facilitate learning by reducing cognitive load through simultaneously presenting information to both systems (i.e. audio and text) (Chandler \& Sweller, 1991; Mayer \& Anderson, 1992; Mayer \& Moreno, 1998; Mayer \& Sims, 1994).

However, recent studies have demonstrated that this so-called multimedia effect is not universal, especially when the information are presented in the visual format through words and pictures. Learners often fail to 
integrate information from multiple sources which are being processed in the same channel. In fact, multiple representations could slow processing of information and reduce performance in both comprehension and knowledge transfer (Gerjets, 2010; Scheiter \& Eitel, 2010; Schuler, Scheiter \& Gerjets, 2010). Kalyuga (2008) noted that main sources of an unnecessary cognitive load in multimedia learning environments are spatially and/or temporally separated elements of information that need to be integrated. Furthermore, if one isolated piece of information is fully intelligible for the learners, then unnecessarily processing of an additional piece of information that has no additional benefit for understanding can result in extraneous cognitive load. Sweller \& Chandler (1994) have called this "the redundancy effect". In addition to redundancy, the reason why the multimedia effect does not always positively influence learning can be found in the situation when there is a trade-off between processing of text and processing of pictures. According to Schnotz \& Bannert (1999), the pictures might replace the text to some extent in the process of comprehension and learning and learner will use the pictures instead of the text, which results in less intensive processing of the text.

\section{Cognitive load in processing of interactive animations}

Whereas static pictures include only visual-spatial information, animated pictures include visual-spatial as well as temporal information. This defining feature of animated pictures could support construction of dynamic mental models. Animations allow a direct activation of dynamic perceptual schemata, which is not as easily achievable with static pictures (Schwan \& Riempp, 2004; Tversky, Heiser, Mackenzie, Lozano, \& Morrison, 2008).

However, animations are possibly not beneficial in all situations. Due to the quick loss of information in working memory, very limited processing can be devoted to the single states within the animation. Therefore, if the learner has to compare different states within a dynamic event, displaying the corresponding states simultaneously through static pictures would provide a much better basis for this kind of requirements (Betrancourt, 2005; Schnotz \& Lowe, 2008). Kalyuga (2008) asserts that one of the main sources of overload in dynamic multimedia is the management of transient nature of dynamic information. The transient information should be kept active in working memory while simultaneously more upcoming information is being processed, which leads to overload of the working memory.

A recent development in multimedia learning environments is the use of interaction between the learner and the animation which is especially important in learning physics topics. For example, interactive animations can permit the learner to manipulate the frequency and intensity of light that is incident on a metal surface, when investigating how these two variables affect the emission of photoelectrons. In other words, interactive animation allow for testing of hypotheses about physical phenomena under specific conditions. One more desirable feature of interactive animations is that they allow the learners to control their own learning by controlling the pace of the animation (by speeding up or slowing down the rate of display) In addition, interactive animations sometimes allow learners to perform cognitive processes that had otherwise been very difficult to implement due to tasks that put high demands on the WM capacity (Rasch \& Schnotz, 2009).

Interactive multimedia learning environments have the potential of more efficient management of cognitive load compared to traditional media. Kayluga (2008) suggests several ways in which interactivity in multimedia learning environment contributes to the management of various sources of cognitive load. First of all, it should be noted that providing feedback on student responses facilitates development of deep understanding of the material, whereby explanatory feedback is to be preferred over corrective feedback (Johnson \& Priest, 2014). As a matter of fact, explanatory feedback may assist in balancing the executive functions between existing knowledge and instructional guidance (Kayluga, 2008). As learners acquire more experience the focus of instruction moves from detailed explanations to problem-solving or exploration, which in turn further increases learner expertise. However, interactive exploratory learning environment can be very demanding and may generate cognitive overload for novice learners. An interactive learning environment that includes communicational level of interactivity can increase germane load, by prompting the learners for self-explanation and prediction.

\section{Physlets}

Physlets are small, flexible and interactive animations whose design was guided by the results of physics education research (Christian \& Belloni, 2001). Christian \& Belloni (2013) have developed a broad collection of Physlets that cover almost all introductory physics topics typically taught at the university level. This collection 
of Physlets can be accessed freely at https://www.compadre.org/physlets.

Physlets allow for multimodal learning by demonstrating the physical phenomena through vivid visualizations, accompanied by providing the corresponding graphs, diagrams and tables. According to Krusberg (2007) presenting of a physics concept by combining multiple representations promotes development of conceptual understanding. In addition, it should be noted that Physlets allow the students to control their own pace of learning - typically, students can easily start and stop animations, collect measurement of various quantities and control the position of objects within the active window. Since physics deals often with dynamic phenomena, Physlets are in general in line with the principle of congruence (Tversky, Morrison, \& Betrancourt, 2002), according to which the content and form of teaching materials should correspond to the contents and form of the presented concept.

For each topic of introductory physics the Physlets collection contains three types of Physlets (Christian \& Belloni 2004): illustrations, explorations and problems. Physlet-illustrations are mainly aimed for facilitating the introduction of new physical concepts within the context of vividly represented physical phenomena. Physletexplorations allow further investigation of the introduced physical concept. They are mostly designed in line with the idea of guided inquiry, with worksheets provided for all explorations. Thereby, learners are expected to set and test hypotheses about physical phenomena, and to explore relationships between physical quantities, in general. For learning about optical elements most Physlet-explorations are situated within the context of experimenting with various objects (point sources, beam sources, mirrors, lenses) on an optical bench, whereby light rays are used for explaining the creation of optical images and the user is allowed to take measurement of coordinates for purposes of gathering information about the relevant distances.

Finally, Physlet-problems represent problems in which at least part of the problem-stem is provided in the form of an animation. Here students are typically expected to analyze the dynamic visualization of a given phenomenon with the purpose of finding the unknown value of a physical quantity or to find the relationship between various quantities. While interacting with Physlet-problems students receive much less external guidance compared to the use of Physlet-explorations. Figure 1 shows a screenshot from Physlet-problem 33.1 which is related to the topic of concave mirrors.

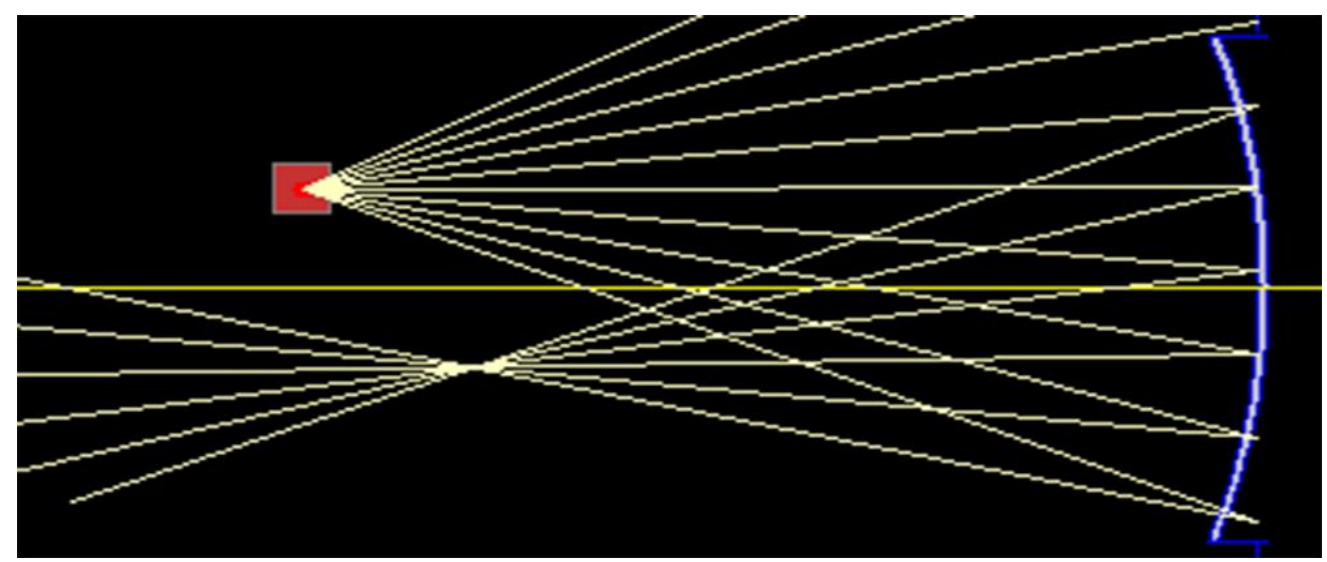

Figure 1. Exploring the focal length of curved mirrors with Physlets

In the above mentioned example the learner is expected to find the focal length of a given concave mirror, whereby the learner is shown a divergent beam of light rays emanating from a light source which can be freely moved to any position in the animation window. The learner is expected to realize that only light rays that are passing through the focal point are parallel with the optical axis after being reflected from the mirror. Such a situation is obtained when the source of the divergent light beam is dragged to the position of the focal point. Now it is sufficient to read the coordinates of the mirror and the light source in order to find the distance between these two objects which in this particular situation represents the focal length of the mirror. It should be noted that compared to traditional physics problems, Physlet-problems better resemble real-world problem situations. As a matter of fact, in the verbal part of the Physlet-problem stems typically it is being avoided to explicitly provide information about the type of object's motion, as well as about the values of relevant physical quantities. However, the visual part of the problem stem provides means to access more information than it is needed for solving the problem. Thereby, from a large amount of information (much of these being redundant) the learner has to identify relevant information, collect measurements and analyze the collected data for purposes of solving the problem (Dancy, Christian, \& Belloni 2002).

There are only a few journal articles that describe pedagogical features of Physlets and/or effects of Physletbased teaching. Bonham, Risley, \& Christian (1999) described the use of Physlets in teaching electrostatics, 
Cox, Belloni, Christian, \& Dancy (2003) in thermodynamics, Dancy, Christian \& Belloni (2002) in optics and Belloni, Christian, \& Cox (2007) in quantum mechanics. Cox et al (2003) found that the use of Physlets has the following advantages for teaching thermodynamics: 1) allows interactive visualization of abstract concepts; 2) stimulates students to use more advanced problem-solving strategies; and 3) provides the possibility of direct insight into the effect of applying a change of system parameters. Results of the studies conducted by Ulen, Čagran, Slavinec, \& Gerlič (2014) and Ulen, Gerlič Slavinec, \& Repnik (2017) indicate that Physlets contribute to conceptual learning more than traditional teaching. Similar results were obtained in the study conducted by Mešić, Dervić, Gazibegović-Busuladžić, Salibašić, \& Erceg (2015).

\section{Research on Teaching and Learning about Lenses}

Earlier research shows that many student have misconceptions about the mere mechanism of image formation by a lens. Knight (2004) comments that a substantial number of students think there is a "potential image" that travels as a whole from the object to the screen where it is given realization. Therefore it is important to consistently use the point-to-point correspondence between object and image when explaining image formation by a lens (Viennot, 2003). To that end it is advisable to point out that light rays emanate from all points (and in all directions) of a bright object (Arons, 1997). It is also important to emphasize that image is formed by a lens no matter whether there is a screen or not (see Goldberg \& McDermott, 1987). Knight (2004) suggests that effective teaching about lenses should take into account students' difficulties with the ray model of light, as well as to include a clarification of the role of principal rays, the lens and the screen in image formation. Finally, it is also important to explain the role of the eye in "seeing the image".

\section{Present Study}

Tversky, Morrison, \& Bétrancourt, (2002) suggest that, ,interactivity may be the key to overcoming the drawbacks of animation as well as enhancing its advantages" (pp. 258). The interactivity of Physlets allows the learner to control different aspects of the visual display. They can view and review, stop and start, change key values, monitor effect of the changes, and study all aspects of the visual display that they need. In addition, interactivity allows the learners to take active role in their learning. Compared to static pictures, interactive animations can stimulate more elaborated cognitive processing. Physlets are particularly suitable for exploring the point-to-point correspondence between object and image which proves to be very important for developing understanding about image formation by lenses (Viennot, 2003). It also allows for tracing a large number of light rays emanating in different directions from one and the same point of the object. According to Arons (1997, p. 260) showing a divergent bundle of rays emitted from each object point may help the students to develop a better understanding about the process of image formation.

When it comes to the traditional framework of learning it should be noted that it is based on the assumption that knowledge is transferable through verbal explanation of the learning material to students who are more or less passive listeners. Due to practical reasons, in traditional static visualizations typically only the principal light rays are traced which sometimes results in poor understanding of the role of principal rays in image formation (Knight, 2004). Therefore interactive animation can be a more efficient learning environment compared to traditional, expository instruction. However, interactive animation may require additional cognitive resources. Therefore, generally, it can be assumed that interactive pictures create additional extraneous load which potentially impedes learning. Consequently, the first aim of our study was to investigate the relative efficacy of using Physlets, printed sequences of static pictures generated from Physlets and traditionally presented static pictures for facilitating learning about lenses.

Interactive multimedia learning environments have the potential of more efficient management of cognitive load and thus more efficient learning. According to Schnotz \& Rasch, (2005), interactive animation could have enabling, facilitating or detrimental function. The enabling function manifests itself in the situation when animation reduces the cognitive load in order to allow cognitive processing that would otherwise be impossible. If the task could be solved only with high mental effort and interactive animation reduces cognitive load of task, then animations will have a facilitating function. Therefore, one could assert that interactive animation reduces extraneous cognitive load and create additional germane load. However, interactive animation may also impose additional cognitive load due to the need of making decisions about which manipulations should be executed and additional search processes, in general. Consequently, interactive animations may also have a detrimental function, manifested in an increase of extraneous cognitive load and reduction of germane load. When it comes to intrinsic load, it should be noted that it is determined by the complexity of the information to be learned or 
problem to be solved. Therefore, it can be assumed that the same structure of learning material across different teaching methods (Physlets, printed sequences of Physlets-based pictures, traditionally presented static pictures) imposes the same intrinsic cognitive load, given that learners have equal prior knowledge. In line with these assumptions, the second aim of our study was to investigate the effects of using Physlets, printed sequences of static pictures and traditionally presented static pictures on intrinsic, extraneous and germane cognitive load.

\section{Methods}

\section{Participants}

Our study included 49 high-school students from three parallel school classes at the Sarajevo Second Gymnasium (Bosnia and Herzegovina). The sample has been obtained by means of convenience sampling. The average age of the participants was 16.14 years $(\mathrm{SD}=1.25)$ and $53.7 \%$ of participants were female. Seventeen students from one randomly selected class were taught with Physlets. Another fifteen students from the second randomly selected class were taught with sequences of Physlets-based static pictures. Finally, the third group consisted of seventeen students who received the traditional treatment characterized by traditional presentation of static pictures.

\section{Materials}

In the three treatment groups different learning materials were used. Within the traditional treatment group the students learned from static pictures that were drawn on the blackboard. In the two remaining groups, students learned from Physlets (Christian \& Belloni, 2013) and from printed sequences of Physlets-based static pictures, respectively. All learning materials presented the same learning topic which was lenses. This topic was part of the regular curriculum. For all treatment groups, we prepared learning materials in which illustrations are followed by explorations and problems. The purpose of illustrations was to vividly introduce the most important concepts. On the other hand, explorations were supposed to facilitate exploration of specific physical phenomena, and problems were expected to provide effective contexts for elaboration and application of knowledge.

\section{Physlets}

Physlet-based learning materials were obtained from the second edition of the Physlet physics book (Christian \& Belloni, 2004) that can be freely accessed at: https://www.compadre.org/physlets/. In total, eleven Physlets from the above mentioned book were used in the classes: two Physlet-illustrations (convex and concave lenses), five Physlet-explorations (characteristic rays, focal length, distance between figure and curvature of lens, position of image with respect to object's position) and four Physlet-problems (image formed by convex lens, focal length of convex lens, point sources and beam sources of light, systems of two convex linses).

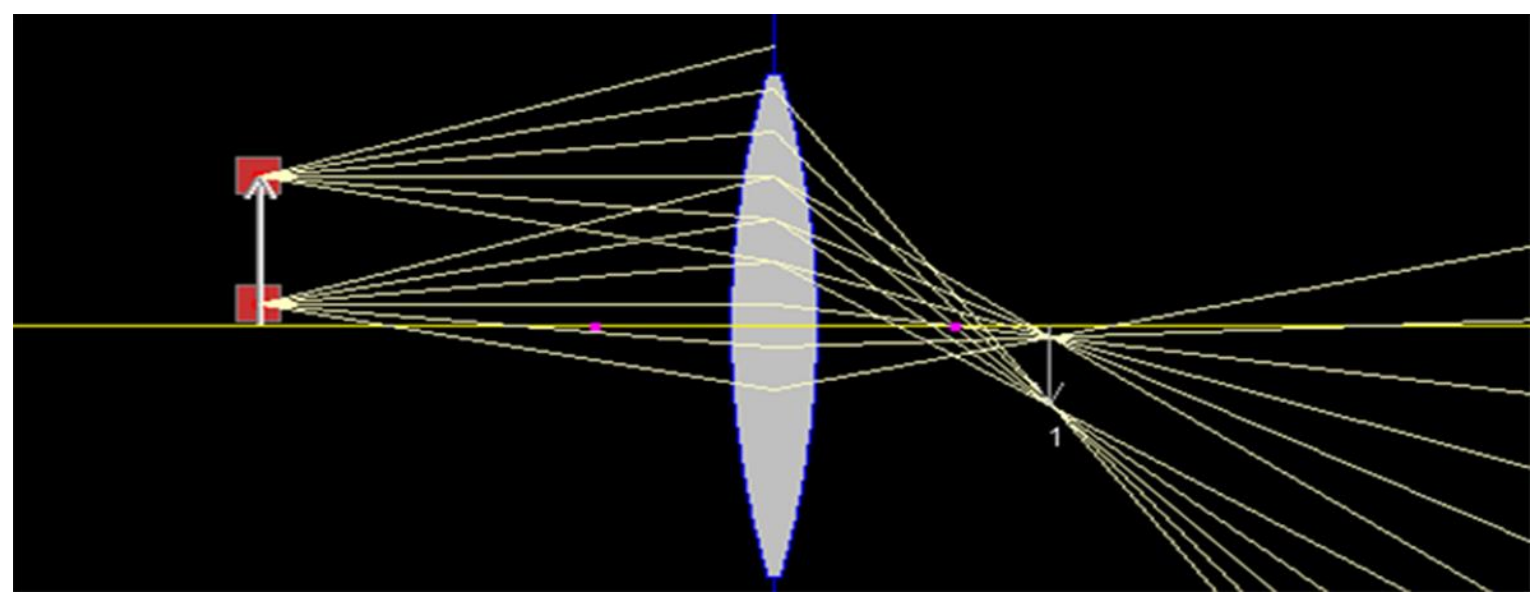

Figure 2. Exploring the image formation by a convex lens for an extended object

Figure 2 shows a screenshot from a simulation in which the learner has on her/his disposal an optical bench, a bright object and a biconvex lens. This simulation allows exploration of image formation by a converging lens. 
Concretely, the learner is allowed to move the bright object along the optical bench and to observe how moving the object affects the position and height of the image. As the object is moved along the optical bench the learner can observe how the ray diagram changes. Quantitative conclusions about image formation can be drawn by measuring the coordinates of object, lens and image. Thereby, learners were guided through exploration activities through the use of corresponding worksheets that are part of the Physlets-package.

\section{Sequences of Physlets-based static Pictures (static Physlets)}

Similar to animated cartoons, each Physlet inherently contains an enormous number of static pictures associated with the different states of the simulated physical system. For example, the user can change the position of an object in multiple ways which results in multiple different positions of the object's image. In one of the treatment groups, the learning material was obtained by extracting from each Physlet multiple static pictures (typically 3 or 4 pictures) that showed those states of the animated system that we considered to be most relevant for learning.
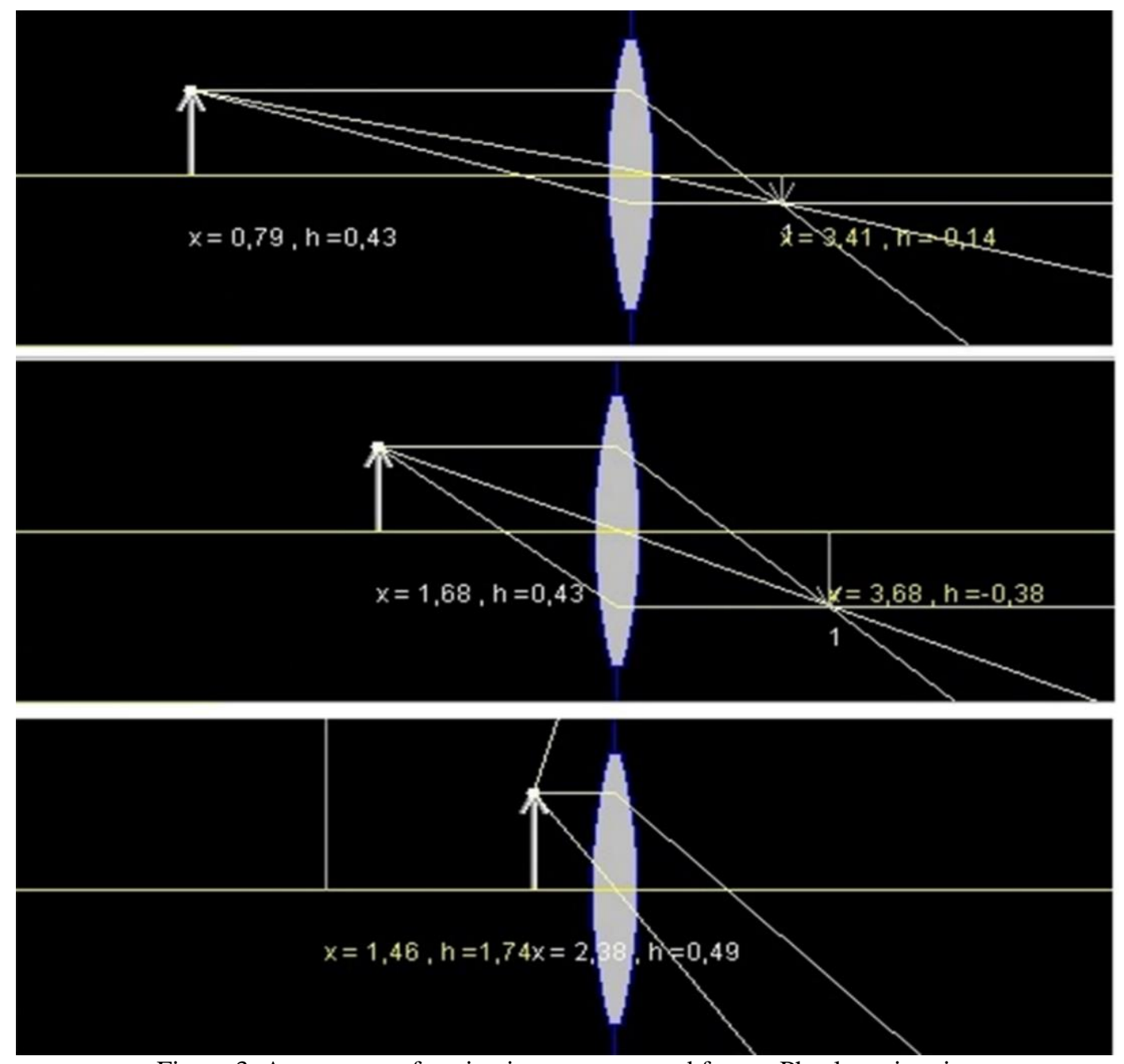

Figure 3. A sequence of static pictures generated from a Physlet animation

Figure 3 shows the sequence of three static pictures that illustrate three characteristic "object-image" situations generated from the earlier discussed optical bench Physlet. The three pictures were generated by means of the print screen feature. These sequences of static pictures were available to students in printed form, whereby the sequences related to explorations were accompanied with worksheets and the sequences related to problems were accompanied with the written version of the problem stem. The nature of the learning material did not allow the students to interact directly with the teaching material. Although the students could not interact with this type of visualization in the way it was possible with dynamic Physlets, they could infer the cause and effect relationships from the visualizations that were pre-prepared for them by the teacher. 


\section{Traditional static pictures}

Traditional static pictures were drawn by the teacher on the blackboard. The teacher drew on the blackboard pictures that can be considered as traditional analogues of pictures that were provided in printed form to the static Physlets group. In some occasions simply the sequences of pictures that were provided to the one group in printed form were drawn on the blackboard for the traditional group. For example, for purposes of illustrating image formation by a lens, on blackboard the three illustrations from Figure 3 were drawn. However, in most other occasions the teacher attempted to represent a physical situation within a single picture (instead of using a whole sequence of pictures) which is typical for the traditional approach. An additional difference between the traditional approach and the two earlier described approaches was that students from the traditional group were not provided with worksheets that guided the analysis of some visualizations in the other two groups. As a matter of fact Physlets-based explorations are accompanied with worksheets that may guide the learner through the process of taking measurements and analyzing data. In other words, Physlet-based materials (both, dynamic and static) prove to be more compatible with the guided inquiry instruction because they explicitly include the requirement of analyzing (visual) data with the purpose of constructing new knowledge.

\section{Measures}

\section{Prior knowledge}

As a measure of physics prior knowledge the half-year report grades in physics were used. The range of grades was between 3 to 7 on a scale from 1 to 7 . The arithmetic mean was $\mathrm{M}=4.67$ ( $\mathrm{SD}=1.07)$. Analysis of variance showed that the between-group difference in average physics grades was not statistically significant $(\mathrm{F}(2,46)=1.03, \mathrm{p}=0.36)$. Bonferroni post hoc analyses showed that for none of the multiple comparisons (Physlets vs static Physlets, Physlets vs Traditional, Static Physlets vs Traditional) a statistically significant effect could be found.

\section{Cognitive Load Questionnaire}

The intrinsic, extraneous and germane cognitive load were measured by an instrument initially developed by Leppink, Pass, Van der Vleuten, Van Gog, \& Van Merrienboer (2013). That instrument consists of ten items. Thereby, three items measure intrinsic, three extraneous and four germane load. The results of a study conducted on a sample from Bosnia \& Herzegovina (Zukić, Đapo, \& Husremović, 2016) indicate satisfactory validity and high reliability of the instrument. In our study the Leppink's instrument has been administered three times - after illustrations, explorations and problems, respectively. For the germane load subscale Cronbach's alpha amounted to 0.8, 0.92 and 0.95, while for the extraneous load it amounted to 0.46, 0.63 and 0.63. Finally, for intrinsic load the Cronbach's alpha amounted to $0.69,0.84$ and 0.69 , for the three chosen time points.

Table 1. A brief description of posttest items

\begin{tabular}{|c|c|c|c|c|c|c|}
\hline Item 1 & Item 2 & Item 3 & Item 4 & Item 5 & Item 6 & Item 7 \\
\hline $\begin{array}{l}\text { Determining } \\
\text { the type of } \\
\text { lens from the } \\
\text { visual } \\
\text { representation } \\
\text { of light ray } \\
\text { propagation } \\
\text { though "black-box" } \\
\text { "bla }\end{array}$ & $\begin{array}{l}\text { Describing } \\
\text { image } \\
\text { (nature, } \\
\text { position, } \\
\text { height) for } \\
\text { different } \\
\text { distances of } \\
\text { the object } \\
\text { from the } \\
\text { biconvex } \\
\text { lens }\end{array}$ & $\begin{array}{l}\text { Determining } \\
\text { the type of } \\
\text { lens from the } \\
\text { visual } \\
\text { representation } \\
\text { of light ray } \\
\text { propagation } \\
\text { through a } \\
\text { "black-box" } \\
\text { (multiple } \\
\text { boxes) }\end{array}$ & $\begin{array}{l}\text { What is the } \\
\text { focal length } \\
\text { of the } \\
\text { concave lens } \\
\text { (object and } \\
\text { image } \\
\text { position } \\
\text { explicitly } \\
\text { provided)? }\end{array}$ & $\begin{array}{l}\text { What is the } \\
\text { focal length } \\
\text { of the lens } \\
\text { system (focal } \\
\text { lengths of } \\
\text { individual } \\
\text { lenses and } \\
\text { their } \\
\text { separation } \\
\text { explicitly } \\
\text { provided)? }\end{array}$ & $\begin{array}{l}\text { What is the } \\
\text { focal length } \\
\text { of the lens } \\
\text { system? } \\
\text { (focal } \\
\text { lengths and } \\
\text { their } \\
\text { separation } \\
\text { must be } \\
\text { inferred from } \\
\text { a picture } \\
\text { before } \\
\text { calculation) }\end{array}$ & $\begin{array}{l}\text { Construct a } \\
\text { ray diagram } \\
\text { for the given } \\
\text { object and } \\
\text { concave lens } \\
\text { and discuss } \\
\text { the } \\
\text { characteristics } \\
\text { of the } \\
\text { obtained } \\
\text { image }\end{array}$ \\
\hline $\begin{array}{l}\text { Multiple- } \\
\text { choice }\end{array}$ & $\begin{array}{l}\text { Two-tier } \\
\text { multiple- } \\
\text { choice }\end{array}$ & $\begin{array}{l}\text { Two-tier } \\
\text { multiple- } \\
\text { choice }\end{array}$ & Open-ended & Open-ended & Open-ended & Open-ended \\
\hline
\end{tabular}




\section{Knowledge test (learning outcome)}

Students' learning outcomes were examined by a Knowledge test which was constructed for the purpose of this study. It consists of seven items and measures students' understanding about lenses. A brief description of the test items is provided in Table 1. Generally, we attempted to align the test items with contents that had been covered within the teaching treatments. Each completely correct answer was credited with one point which means that, theoretically, the posttest scale ranged from 0 to 7 . There was no time limit imposed for completing the test.

\section{Procedure}

The study was conducted in one learning session lasting about 90 minutes for each group. For each group, the session consisted of three parts: firstly illustrations were shown, followed by explorations and problem-solving activities. The pictures, animations and drawings were accompanied by the spoken instruction and explanation. During Physlet-based sessions, presentations were projected on the screen, while teacher and volunteering students altered parameters and interacted with Physlets. The teacher started and guided the discussion. The students participated in the discussion and entered their predictions, observations and conclusions into their worksheets (for exploration activities).

In the approach characterized by use of sequences of static Physlet-based pictures, the students got the printed version of static Physlet-pictures and the same worksheets as the students from the Physlet group. Unlike students from the Physlet group, in the "sequences of printed pictures" group students were not able to track the dynamic consequences of altering parameters of the physical setting. For example, in the Physlet group one could change focal lengths of lenses (in infinitely many ways) and observe how this affects refraction of the beam in "real-time", while in the sequences of static pictures group the students were only presented with a few printed images showing refraction on lenses that have different focal lengths.

In the traditional teaching group visualization of concepts was achieved by using the blackboard. The teacher adapted examples of physical situations so that they matched as close as possible the examples used in the Physlets-based treatments. The problem-solving sessions in the traditional group were different compared to corresponding sessions in the other two groups. Specifically, for each problem, only one student was asked to solve the problem on the board, in front of the class, whereas other students were expected to analyze the modeled problem-solving process and to compare it with their own ideas. After each session part (illustration, exploration and problems) students in all groups completed the Instrument for measuring intrinsic, extraneous and germane cognitive load. At the end of the learning session, students also completed the Knowledge test.

\section{Results}

\section{The Effect of Teaching Method on Learning Outcome}

For purposes of investigating the effect of teaching method (traditional, static Physlets, Physlets) on understanding of lenses we conducted a one-way ANCOVA, controlling thereby for the effect of students' prior knowledge. Figure 4 illustrates the effect of different teaching methods on students' level of understanding about lenses. On average, students from the Physlet-groups scored 84,0 \% on the optics test, while students from the groups who used static Physlet pictures and a traditional approach scored $68.5 \%$ and $63.8 \%$, respectively.

The main ANCOVA analysis has been preceded by an exploration of the relationship between students' previous knowledge and students' level of understanding of lenses. Thereby, the Pearson's coefficient of correlation $(\mathrm{r}=0.358 ; \mathrm{p}=0.012)$ was found to be moderate and statistically significant which justifies the inclusion of the covariate into the statistical model. Our data met the ANCOVA assumptions. Specifically, it has been found that the covariate is independent of treatment effects (level of prior knowledge was the same across the three teaching methods) $(\mathrm{F}(2,46)=1.032 ; \mathrm{p}=0.364)$. In addition, our data also met the homogeneity of regression slopes assumption (regression slopes for the relationship between level of understanding and previous knowledge were the same across groups $(\mathrm{F}(2,48)=0.427 ; \mathrm{p}=0.655)$, as well as the homogeneity of error variances assumption $(\mathrm{F}(2,46)=2.365 ; \mathrm{p}=0.105)$. We found a statistically significant effect of teaching method on the level of understanding about lenses, after controlling for effects of previous knowledge $\left(\mathrm{F}(2,48)=8.316, \mathrm{p}=0.001\right.$, partial $\left.\eta^{2}=0.27\right)$. Bonferroni post hoc analysis showed statistically significant 
differences between the traditional teaching methods and Physlets-based method $(\mathrm{p}=0.001)$, whereas the difference between the Physlets-based method and static Physlets was (barely) not statistically significant $(\mathrm{p}=0.063)$. A comparison between the traditional teaching method and static Physlets method showed that the difference in level of understanding about lenses proved to be statistically non-significant $(\mathrm{p}=0.424)$.

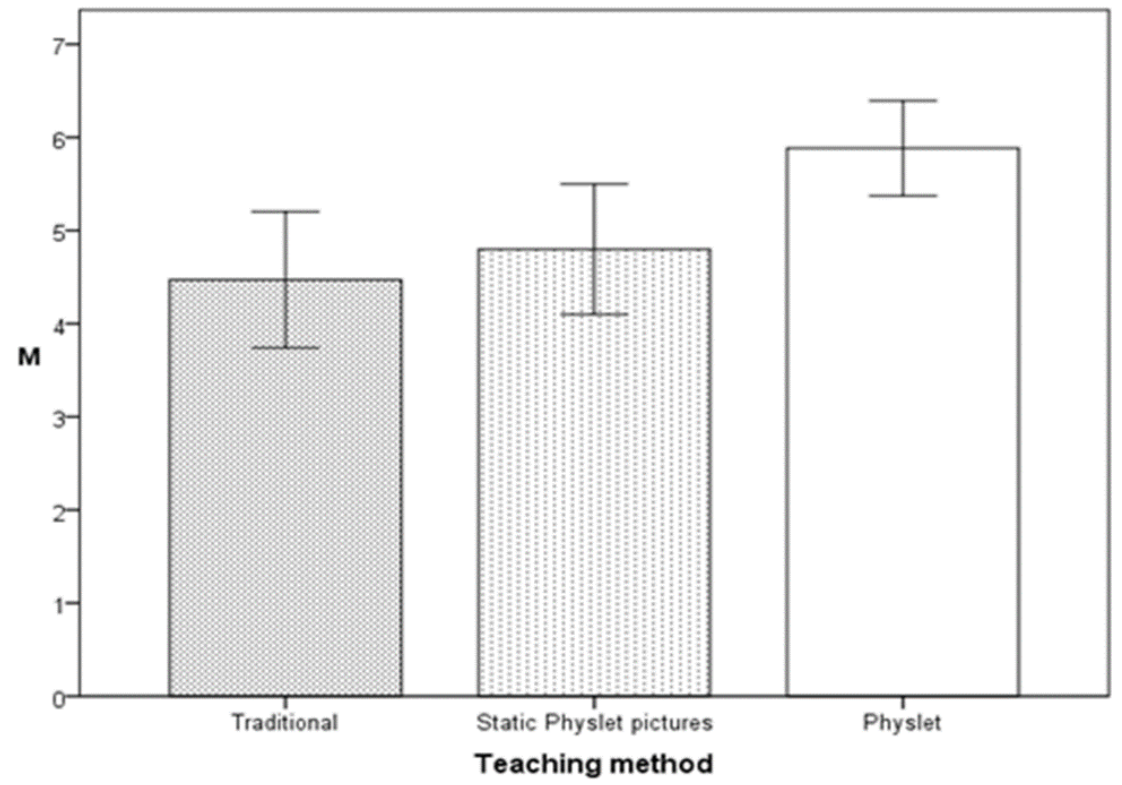

Figure 4. Means and corresponding $95 \%$ confidence intervals of the mean on the knowledge test about lenses for each teaching method

\section{The Effect of Teaching Method on Cognitive Load}

In order to investigate the effect of teaching method (traditional, static Physlets, Physlets), category of instructional content (illustrations, explorations and problems) and type of cognitive load (intrinsic, extraneous, germane) on self-reported cognitive load, a mixed ANCOVA was conducted. The categories of instructional content (illustration, exploration and problem) and type of cognitive load (intrinsic, extraneous and germane) were within-subjects factors and teaching method (traditional, static Physlets, Physlets) was between-subjects factor. For purposes of controlling for the effect of prior knowledge on cognitive load, we calculated the Pearson's correlation coefficients between half-year report grades in physics and self-reported cognitive load as measured by the Cogntive load questionnaire. Taking into account that these correlational analyses resulted with low and statistically non-significant correlations we decided not to include a covariate into the statistical model. Mauchly's sphericity test has been used for purposes of exploring the assumption of homogeneity of error variance. The Mauchly's test proved to be statistically significant for type of cognitive load $\left(\chi^{2}(2)=0.644\right.$; $\mathrm{p}=0.0005 ; \varepsilon=0.737)$, and interaction between type of cognitive load and category of instructional content $\left(\chi^{2}(9)=0.520 ; p=0.001 ; \varepsilon=0.777\right)$, whereby $\varepsilon$ is Greenhouse-Geisser estimate of sphericity. Consequently, for the type of cognitive load variable a Greenhouse-Geisser correction of degrees of freedom has been applied, whereas for the interaction between type of cognitive load and category of instructional contents we applied the Huynh-Feldt correction of degrees of freedom.

For type of cognitive load a statistically significant main effect has been found, $F(1.475,67.838)=59.879$, $\mathrm{p}=0.005$. The mean value of germane load $(\mathrm{M}=6.46)$ proved to be substantially higher compared to the mean value of intrinsic $(\mathrm{M}=3.192)$ and extraneous load $(\mathrm{M}=2.956)$. Bonferroni post hoc analysis indicated that germane load was significantly different from intrinsic $(\mathrm{p}=0.0001)$ and extraneous load $(\mathrm{p}=0.0001)$. We found no statistically significant difference between intrinsic and extraneous load.

Furthermore, the interaction between type of cognitive load and teaching method proved to be statistically significant, $F(4,92)=3.627, p=0.009$. Mean values of three types of cognitive load for the three teaching approaches are shown in Figure 5. Bonferroni post hoc analyses have been applied for investigating the statistical significance of simple main effects of the teaching method variable at different levels of the type of cognitive load variable. The only statistically significant effect $(p=0.014)$ has been found for germane load comparison between the traditional and Physlet teaching methods. 


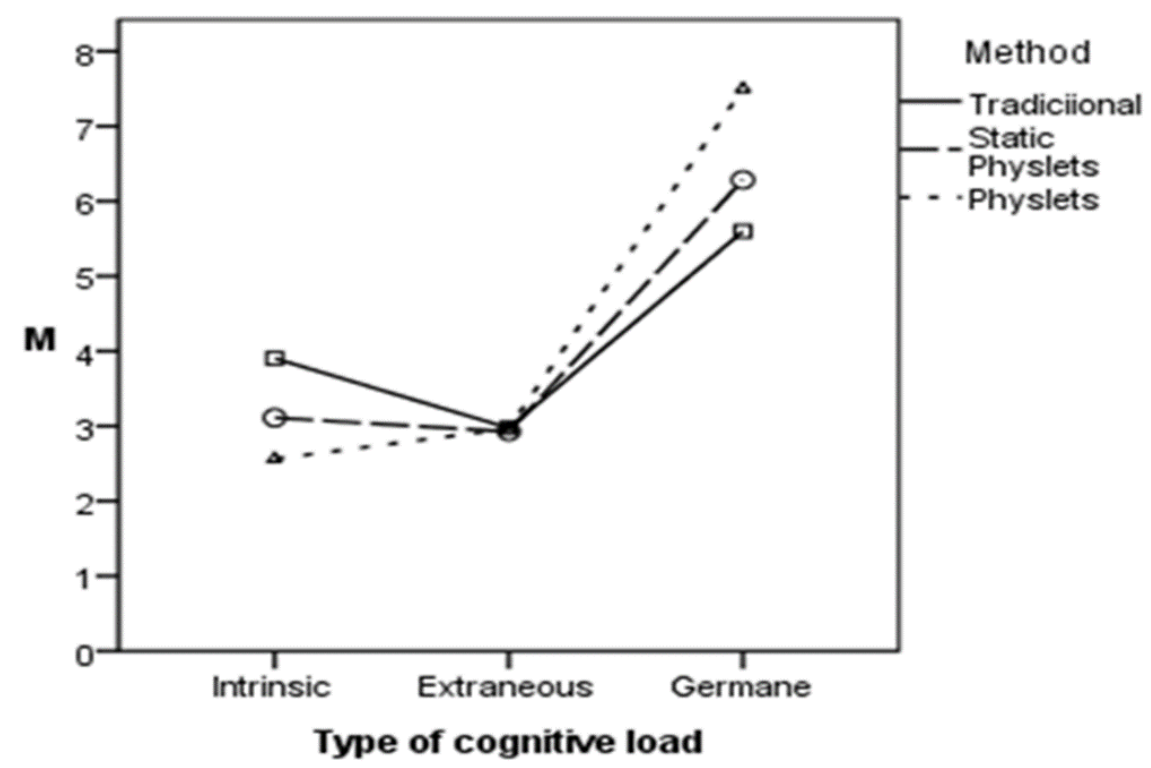

Figure 5. Mean values of three types of cognitive load for each teaching approach

We have found neither a statistically significant effect of category of instructional content $(F(2,92)=0.446$; $\mathrm{p}=0.642$ ), nor a statistically significant interaction between category of instructional content and teaching method $(\mathrm{F}(4,92)=1.353 ; \mathrm{p}=0.257)$. On the other hand, the interaction between type of cognitive load and category of instructional content proved to be statistically significant, $F(4,184)=4.554 ; p=0.002$. Figure 6 show s the mean values of different types of cognitive load at different levels of the instructional content variable. We conducted Bonferroni post hoc analyses of simple main effects of the type of instructional content variable at each of the levels of the type of cognitive load variable. Statistically significant differences have been found for the illustration versus problems comparison $(\mathrm{p}=0.009)$, as well as for the exploration versus problem comparison $(\mathrm{p}=0.029)$. In addition, it has been found that illustrations significantly differ from problems, when it comes to the induced germane load $(\mathrm{p}=0.024)$.

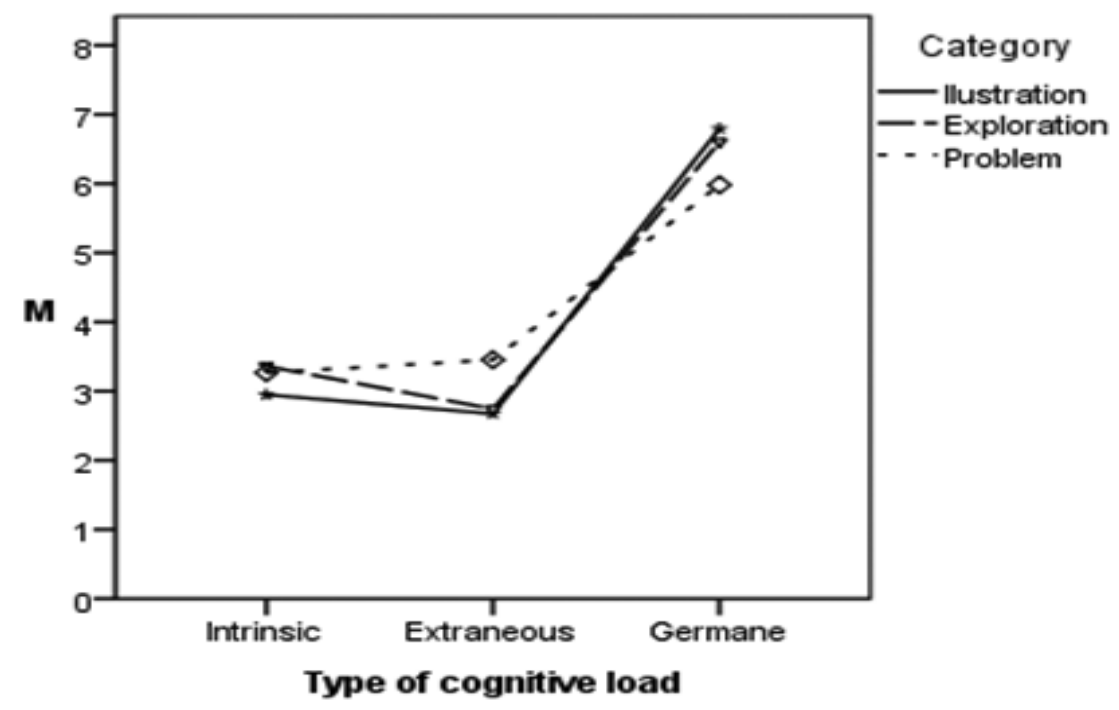

Figure 6. Mean values of type of cognitive load at the three levels of instructional content

Finally, we have found a statistically significant interaction between the type of cognitive load, category of instructional content and teaching approach, $F(8,184)=4.797, p=0.0001 ; \eta^{2}=0.173$. Figure 7 shows the mean values of the three types of cognitive load for the three teaching approaches, at each of the three levels of the instructional content variable. 


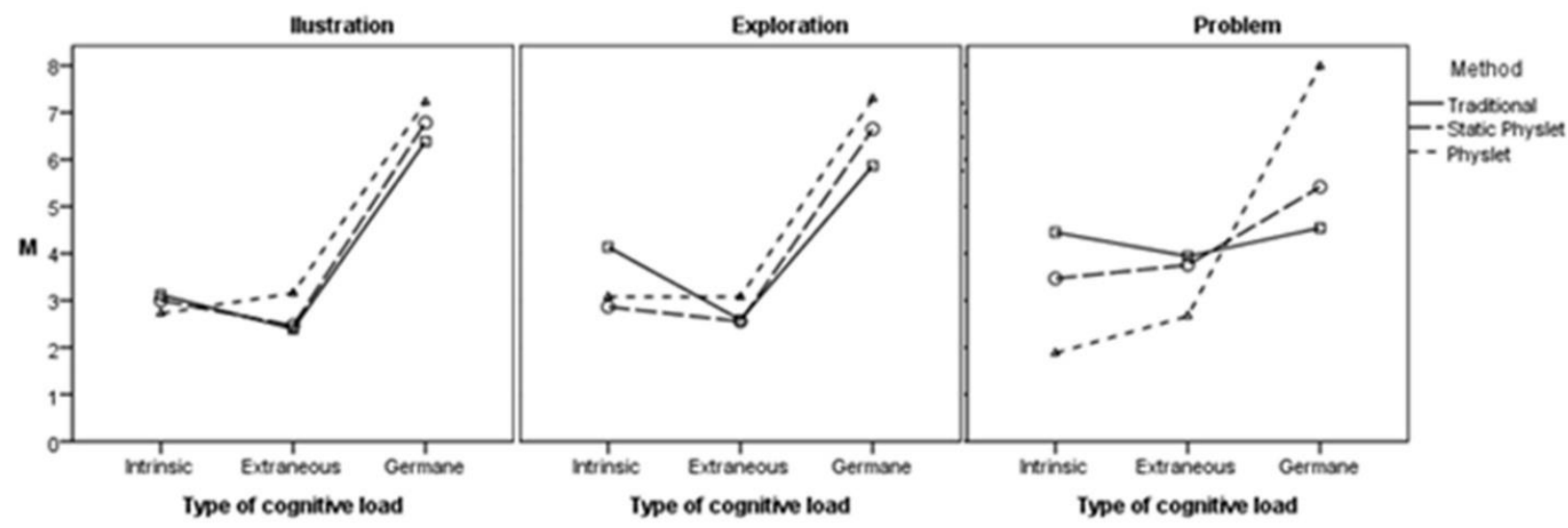

Figure 7. Mean values of the three types of cognitive load for the three teaching methods, at each of the three levels of the instructional content variable

For each of the instructional content categories Bonferroni post hoc analyses have been conducted with the purpose of exploring the statistical significance of simple main effects of the teaching approach variable at each level of the type of cognitive load variable. Unlike for illustrations and explorations, for the problems category we have found statistically significant interactions between the teaching approach and type of cognitive load. When it comes to problem-solving, the lowest intrinsic load has been found for teaching with Physlets. Intrinsic load for solving Physlet problems was significantly lower than intrinsic load related to solving problems in the traditional $(\mathrm{p}=0.0001)$ and static Physlets approach $(\mathrm{p}=0.041)$. Just the opposite pattern has been found for germane load. The germane load related to solving Physlet problems was significantly higher than germane load related to solving problems in the traditional $(\mathrm{p}=0.001)$ and static Physlets approach $(\mathrm{p}=0.023)$.

\section{Discussion}

The first objective of our study was to compare the effectiveness of the Physlet-based approach to teaching about lenses with the traditional and static Physlet approach. It has been found that Physlets-based teaching about lenses is more effective compared to the traditional approach. Similar findings were reported by Ülen et al (2014) for teaching about electricity and Mešić et al (2015) for one-dimensional kinematics instruction. As a matter of fact, the animations allowed the learner to conduct virtual experiments with object and lens on an optical bench which helped them to develop better understanding about the point-to-point correspondence between object and image (see Viennot, 2003). Some Physlets also allowed tracing of a large number of light rays emanating from different points of an object, as well as observing how changing the focal length of a lens influences the propagation of these rays. Analyzing the propagation of a large number of rays probably helped the students to better understand the role of principal rays (Arons, 1997). However, Physlets-based teaching about lenses did not prove to be more effective compared to the approach that utilized sequences of static images, which was not in line with our expectations. This is in line with the results of some earlier studies which indicate that in certain contexts animations are not preferable to static instructional contents (Lewalter, 2003; Mayer, Hegarty, Mayer, \& Campbell, 2005; Mešić et al, 2015; Swezey, 1991). A detailed theoretical account of this effect has been provided by Tversky, Morrison and Bétrancourt (2002). They emphasize the importance of congruence principle which says that the content and form of graphical representations should correspond to the content and form of the taught concept. Consequently, graphical animations are more effective if they are used for purposes of describing spatio-temporal changes. However, according to Tversky, Morrison and Bétrancourt (2002), animations often are not in line with the congruence principle which can explain the results of some studies that show no significant benefits of animations over static images. Furthermore, sometimes animations are not in line with the apprehension principle, which states that structure and content of the external representation need to be timely and correctly perceived and comprehended. Even for relatively simple situations that, for example, include observing the trajectory of a single body, the perception of the observed motion can be flawed (Caramazza, McCloskey, \& Green, 1981; McCloskey, 1983a,b). Furthermore, sometimes animation is perceived by the student as a sequence of discrete events (e.g., Hegarty, 1992; Zacks et al, 2001). If the mere motion is also perceived by the students as a sequence of discrete steps instead as a continuous change, then it is advisable for the content to be presented through a sequence of discrete steps instead through an animation. Tversky et al (2002) conclude that animations sometimes are too complex or presented too fast, which is the main reason why animations sometimes are not more effective than static visual contents. This is particularly true when animations are used for representing complex systems. For representing continuous 
changes well-prepared sequences of static diagrams can be equally effective as animations. Various authors emphasize that some of the limitations of animations can be overcome by the feature of interactivity. As a matter of fact, the possibility to control the animations (e.g., stop, start, step forward, restart) makes it possible to repeatedly inspect some parts of the animation, as well as to focus on specific parts and actions. Animations that allow for interactivity and control can contribute to ensuring a more valid perception and better understanding, in general. However, the results of our study show that in certain contexts even interactive animations are not always preferable to sequences of static images, especially when such images have the potential of activating multiple learning processes (e.g., measuring, goal-directed analysis etc).

The second objective of this study was to investigate the effects of the teaching methods on cognitive load. Firstly, it should be noticed that generally germane load has been found to be significantly higher than the intrinsic and extraneous load. Since germane load is associated with cognitive processes that contribute to learning, the above-mentioned finding could be related to students' satisfactory physics previous knowledge in general, and optics knowledge in particular. Regardless of teaching approach, having the appropriate prior knowledge facilitated comprehension of instructional activities and cognitive engagement. An additional argument for the above-mentioned claim is related to the fact that students' previous knowledge was significantly related to students' achievement on the posttest (i.e., knowledge and understanding about lenses). According to the cognitive load theory, intrinsic load, on the one hand, depends on the number of elements and their interactivity, and on the other hand it depends on students' prior knowledge (Sweller et al, 2011). In our study, an appropriate level of students' previous knowledge led to an optimal level of intrinsic load and relatively high germane load.

Exploration of the interaction between type of cognitive load and teaching methods leads us to the interesting conclusion that germane load is significantly higher for the Physlets-based approach than for the traditional approach, but it is not higher than germane load for the approach that is based on presenting sequences of static images (i.e., static Physlets method). Although intrinsic load is highest for the traditional approach and lowest for the Physlets approach, no statistically significant effect could be detected. In addition, a nearly identical level of extraneous load has been found for all three teaching approaches. These results are in line with the cognitive load principle according to which in multimedia learning extraneous load can be lowered through integration of information and schema building (Brünken, Steinbacher, Schnotz, \& Leutner, 2001; Mayer, 2001). Learning is more facilitated when contents are presented in a way that allows for simultaneous processing of auditory and visual sensory modalities, compared to the situation when contents are only presented through a visual modality (Mayer, 2001). Teaching about lenses primarily required combining visual contents with narratives, whereby there was no need for textual content similar or identical to the narrative. Consequently, the visual channel was not overloaded. All three teaching approaches were in line with that principle which made the level of extraneous load not to differ between the three approaches. On the other hand, the finding that Physlet animations and sequences of static Physlet images induce the same germane load is in line with conclusions by Tversky et al (2002), who emphasize that the efficacy of the dynamics multimedia environment depends on the mere topic that is being taught. Typically, in geometrical optics, the focus is not on observing spatio-temporal changes, which means that a well-prepared sequence of static images can be equally effective as the corresponding animation. The finding that post-treatment understanding of lenses was equal for these two teaching approaches is in line with the result that both approaches led to the same level of germane load. In both approaches the same amount of cognitive resources has been assigned to handling the learning activities and comprehending of physics contents. However, it should be also noticed that, compared to the traditional teaching approach, the Physlet animations and sequences of static Physlet images lead to higher germane load. Sequences of static images were carefully prepared with the purpose to show several characteristic situations that were most relevant for conceptualization of the physical phenomenon (e.g., different characteristic positions of the object on the optical bench). Consequently, these sequences of static images led to the same level of active learning as Physlet animations.

In addition, a statistically significant interaction between type of cognitive load and categories of instructional content has been found. Regardless of teaching method, the extraneous load was found to be significantly higher for problems than for illustrations and explorations. Furthermore, germane load was higher for illustrations than for problems. According to the cognitive load theory, for novices in a certain field problem-based learning can lead to a high extraneous load, and consequently to a low germane load, which hinders effective learning.

Finally, it has been found that the intrinsic load for problem category of instructional content of the Physletsbased method is significantly lower than in the traditional and static Physlets approach. Just the opposite effect has been found for germane load: germane load is significantly higher for the problem category of instructional content of the Physlets-based method than for the other two teaching methods. Physlets-based teaching 
facilitates development of conceptual understanding, particularly within the context of explorations and illustrations. Consequently, students enter the problem solving process with a higher level of knowledge, or at least with a higher level of self-effectiveness, what results with intrinsic load being lower and germane load being higher for the Physlets-based approach compared to the traditional and static Physlet approach. In addition, these findings can be accounted for by the interactive feature which can be only found within the Physlets-based approach. As we have already stated, problem-solving is a cognitively demanding task that typically leads to high extraneous load. However, it seems that the use of interactive simulations motivated the students to engage in minds-on processes and to intensively participate in discussions related to problemsolving. According to Paas, Renkl and Sweller (2003) by assigning the students a more active role in organizing their learning processes, we can motivate them to invest more mental efforts which potentially leads to a higher germane load. For students who learn within collaborative environments the cognitive load induced by the task can be shared between multiple students which decrease the level of cognitive load.

There are some limitations to this study. The first limitation of our study is due to the chosen technique of measuring cognitive load. Measuring of a cognitive load by means of self-report scales is based on the assumption that people have valid insight into their own cognitive processes, and that they are capable to report on the amount of invested cognitive effort. However, subjective estimates often can lead to different, event contradictory results (see de Jong, 2010). Although the Questionnaire for measuring cognitive load has satisfactory construct and predictive validity (Leppink et al, 2013; Zukić, Đapo, \& Husremović, 2016), in future research we suggest using direct measures of cognitive load. The second limitation of this study is related to our sample size. As a matter of fact, larger samples are needed if we wish to increase the power of the statistical tests. Due to the relatively small sample size in our study, we were not in the position to conduct moderation analyses for purposes of investigating the relationship between different types of cognitive load and level of understanding about lenses in function of the teaching approach. Moderation analyses could certainly give additional value to our study. That is why in our future research we plan to include larger sample sizes. Finally, it would be also interesting to investigate whether the relative efficacy of Physlets, static Physlets and traditionally presented static pictures is moderated by the physics content variable.

\section{Conclusion}

Physlet-based teaching about lenses leads to higher germane load and consequently to more effective learning than the traditional approach. As a matter of fact, Physlets' interactivity feature facilitates students' active participation in classroom processes, which results in more intensive engagement with cognitive processes that are relevant for learning. Within the context of teaching about lenses, the benefit of using animations is related to the fact that one can easily trace a large number of rays that emanate from many different points of a bright object which is not easily done within the traditional approach. Changing the position of that object and visualizing how the change of position affects the propagation of light through the lens helps the learner to better understand the point-to-point correspondence between object and image, as well as the role of principal rays (Arons, 1997; Knight, 2004; Viennot, 2003). It seems that, within the context of teaching about lenses, printed sequences of static Physlets accompanied with corresponding worksheets have the potential to trigger similar cognitive processes as dynamic Physlets. Consequently, no statistically significant difference between the dynamic Physlets-approach and static Phylets-approach has been detected.

Generally, the level of effectiveness of a visualization is closely related to its potential to represent an anchoring context for triggering higher cognitive processes and fruitful classroom discussions (Mešić, Hajder, Neumann, \& Erceg, 2016; Rapp \& Curby, 2008). Our study shows that it is advisable to accompany instructional visualizations with explicit tasks that guide the learner through the process of qualitative and/or quantitative analysis of visual data.

\section{References}

Arons, A.B. (1997). Teaching Introductory Physics. New York: John Wiley \& Sons.

Ayres, P., \& Sweller, J. (2005). The split-attention principle in multimedia learning. In R. E. Mayer (Ed.), The Cambridge handbook of multimedia learning (pp. 135-146). New York, NY: Cambridge University Press.

Baddeley, A. (1992). Working memory: The interface between memory and cognition. Journal of Cognitive Neuroscience, 4, 281-288. doi: 10.1162/jocn.1992.4.3.281 
Belloni, M., Christian, W., \& Cox, A. J. (2007). Teaching qualitative energy-eigenfunction shape with Physlets. The Physics Teacher, 45, 488-491. doi: 10.1119/1.2798360

Betrancourt, M. (2005). The animation and interactivity principles in multimedia learning. In R. E. Mayer (Ed.), The Cambridge handbook of multimedia learning (pp. 287-296). New York: Cambridge University Press.

Bonham, S. W., Risley, J. S., \& Christian, W. (1999). Using Physlets to teach electrostatics. The Physics Teacher, 37, 276-280.

Brünken, R., Steinbacher, S., Schnotz, W., \& Leutner, D. (2001). Mentale Modelle und Effekte der Präsentations und Abrufkodalität beim Lernen mit Multimedia [Mental models and the effects of presentation and retrieval mode in multimedia learning]. Zeitschrift für Pädagogische Psychologie, 15, $15-27$.

Caramazza, A., McCloskey, M.\&Green, B. (1981). Naive beliefs in "sophisticated" subjects: misconceptions about trajectories of objects. Cognition, 9, 117-123.

Chandler, P., \& Sweller, J. (1991). Cognitive load theory and the format of instruction. Cognition and Instruction, 8, 293-332. doi: 10.1207/s1532690xci0804_2

Christian, W. \& Belloni, M. (2001). Physlets: Teaching Physics with Interactive Curricular Material. Upper Saddle River, NJ: Pearson Education.

Christian, W., \& Belloni, M. (2004). Physlet Physics: Interactive Illustrations, Explorations and Problems for Introductory Physics. Upper Saddle River, NJ: Pearson Education.

Christian, W., \& Belloni, M. (2013). Physlet Physics 2E: Interactive Illustrations, Explorations and Problems for Introductory Physics $-2^{\text {nd }}$ Edition Pre-release. Available from: http://www.compadre.org/Physlets/index.cfm.

Cox, A. J., Belloni, M., Dancy, M., \& Christian, W. (2003). Teaching thermodynamics with Physlets ${ }^{\circledR}$ in introductory physics. Physics Education, 38, 433-440. doi: 10.1088/0031-9120/38/5/309

Dancy, M., Christian, W., \& Belloni, M. (2002). Teaching with Physlets ${ }^{\circledR}$ : Examples from optics. The Physics Teacher, 40, 494-499. doi: 10.1119/1.1526622

De Jong, T. (2010). Cognitive load theory, educational research, and instructional design: some food for thought. Instructional Science, 38, 105-134. doi: 10.1007/s11251-009-9110-0

Fui-Theng, L. E. O. W., \& Mai, N. E. O. (2014). Interactive multimedia learning: Innovating classroom education in a Malaysian university. TOJET: The Turkish Online Journal of Educational Technology, 13, 99-110.

Gerjets, P. (2010). Bridge over troubled water: from cognitive science to designing digital instruction. Keynote speech at the 32nd Annual Meeting of the Cognitive Science Society. Portland, OR.

Goldberg, F. M., \& McDermott, L. C. (1987). An investigation of student understanding of the real image formed by a converging lens or concave mirror. American Journal of Physics, 55, 108-119. doi: $10.1119 / 1.15254$

Hegarty, M. (1992). Mental animation: Inferring motion from static displays of mechanical systems. Journal of Experimental Psychology: Learning, Memory, and Cognition, 18, 1084-1102.

Johnson, C. I., \& Priest, H. A. (2014). The feedback principle in multimedia learning. In R. E. Mayer (Ed.), The Cambridge handbook of multimedia learning (2nd ed., pp. 449-463). New York: Cambridge University Press.

Kalyuga, S. (2008). Managing Cognitive Load in Adaptive Multimedia Learning. New York: Information Science Reference.

Knight, R. D. (2004). Five easy lessons: Strategies for successful physics teaching. San Francisco, CA: Addison Wesley.

Krusberg, Z. A. (2007). Emerging technologies in physics education. Journal of Science Education and Technology, 16, 401-411. doi: 10.1007/s10956-007-9068-0

Kühl, T., Navratil, S. D., \& Münzer, S. (2018). Animations and static pictures: the influence of prompting and time of testing. Learning and Instruction, 58, 201-209.

Lee, K. M., Nicoll, G., \& Brooks, D. W. (2004). A comparison of inquiry and worked example web-based instruction using physlets. Journal of Science Education and Technology, 13, 81-88. doi: 10.1023/B:JOST.0000019640.07432.2b

Leppink J, Paas F, Van der Vleuten CP, Van Gog T, Van Merriënboer JJ. (2013). Development of an instrument for measuring different types of cognitive load. Behavior research methods, 45, 1058-72. doi: 10.3758/s13428-013-0334-1

Lewalter, D. (2003). Cognitive strategies for learning from static and dynamic visuals. Learning and Instruction, 13, 177-189. doi: 10.1016/S0959-4752(02)00019-1

Lowe, R. K., \& Schnotz, W. (Eds.). (2008). Learning with animation. Research implications for design. New York: Cambridge University Press.

Mayer, R. E. (2001). Multimedia learning. New York: Cambridge University Press. 
Mayer, R. E., \& Anderson, R. B. (1992). The instructive animation: Helping students build connections between words and pictures in multimedia learning. Journal of Educational Psychology, 84, 444-452.

Mayer, R. E., \& Moreno, R. (1998). A split-attention effect in multimedia learning: Evidence for dual processing systems in working memory. Journal of Educational Psychology, 90, 312-320.

Mayer, R. E., \& Sims, V. K. (1994). For whom is a picture worth a thousand words? Extensions of a dualcoding theory of multimedia learning. Journal of Educational Psychology, 84, 389-460.

Mayer, R. E., Hegarty, M., Mayer, S., \& Campbell, J. E. (2005). When static media promote active learning: Annotated illustrations versus narrated animations in multimedia instruction. Journal of Experimental Psychology: Applied, 11, 256-265.

McCloskey, M. (1983a). Intuitive physics. Scientific American, 248, 122-130.

McCloskey, M. (1983b). Naive theories of motion. In D. Gentner \& A.L. Stevens (Eds.), Mental Models (pp. 299-324). Hillsdale, NJ: Erlbaum.

Mešić, V., Dervić, Dž.,Gazibegović-Busuladžić, A., Salibašić, Dž., \& Erceg, N. (2015). Comparing the Impact of Dynamic and Static Media on Students' Learning of One Dimensional Kinematics. Eurasia Journal of Mathematics, Science \& Technology Education, 11, 1119-1140.

Mešić, V., Hajder, E., Neumann, K., \& Erceg, N. (2016). Comparing different approaches to visualizing light waves: An experimental study on teaching wave optics. Physical Review Physics Education Research, $12,010135$.

Paas, F., \& Van Merriënboer, J. J. G. (1994). Variability of worked examples and transfer of geometrical problem-solving skills: A cognitive-load approach. Journal of Educational Psychology, 86, 122-133.

Paas, F., Renkl, A., \& Sweller, J. (2003). Cognitive load theory and instructional design: Recent developments. Educational Psychologist, 38, 1-4. doi: 10.1207/S15326985EP3801_1

Paas, F., Renkl, A., \& Sweller, J. (2004). Cognitive load theory: instructional implications of the interaction between information structures and cognitive architecture. Instructional Science, 32, 1-8. Doi: 10.1023/B:TRUC.0000021806.17516.d0

Paas, F., Tuovinen, J. E., Tabbers, H., \& Van Gerven, P. (2003). Cognitive load measurement as a means to advance cognitive load theory. Educational Psychologist, 38, 63-71. doi: 10.1207/S15326985EP3801_8

Rapp, D. N., \& Kurby, C. A. (2008). The 'ins' and 'outs' of learning: Internal representations and external visualizations. In J. Gilbert, M. Reiner \& M. Nakhleh (Eds.), Visualization: Theory and Practice in Science Education (pp. 29-52): Springer Netherlands.

Rasch, T. \& Schnotz, W. (2009). Interactive and non-interactive pictures in multimedia learning environments: Effects on learning outcomes and learning efficiency. Learning and Instruction, 19, 411-422. doi: 10.1016/j.learninstruc.2009.02.008

Scheiter, K. \& Eitel, A. (2010). How to foster the integration of text and diagrams: an eye tracking study on the use of signals in multimedia learning. Poster presented at the 32nd Annual Meeting of the Cognitive Science Society. Portland, OR.

Schnotz, W., \& Bannert, M. (1999). Einflusse der Visualisierungsform auf die Konstruktion mentaler Modelle beim Bild- und Textverstehen [Influences of the visualization format on the construction of mental models during picture and text comprehension]. Zeitschrift fur experimentelle Psychologie, 46, 216-235.

Schnotz, W., \& Lowe, R. K. (2008). A unified view of learning from animated and static graphics. In R. K. Lowe, \& W. Schnotz (Eds.), Learning with animation. Research implications for design (pp. 304 - 356). New York: Cambridge University Press.

Schnotz, W., \& Rasch, T. (2005). Enabling, facilitating, and inhibiting effects of animations in multimedia learning: Why reduction of cognitive load can have negative results on learning. Educational Technology: Research and Development, 53, 47-58. doi: 10.1007/BF02504797

Schuler, A., Scheiter, K. \& Gerjets, P. (2010). Does spatial verbal information interfere with picture processing in working memory? The role of the visuo-spatial sketchpad in multimedia learning. In S. Ohlsson \& R. Catrambone (Eds), Proceedings of the 32nd Annual Meeting of the Cognitive Science Society (pp. 28282833). Austin, TX: Cognitive Science Society.

Schwan, S., \& Riempp, R. (2004). The cognitive benefits of interactive videos: Learning to tie nautical knots. Learning and Instruction, 14, 293-305. doi: 10.1016/j.learninstruc.2004.06.005

Shell, D.F., Brooks, D.W., Trainin, G., Wilson, K.M., Kauffman, D.F., \& Herr, L.M. (2009). The Unified Learning Model. Dordrecht: Springer.

Spector, M. J., Christensen, D. L., Sioutine, A. V., \& McCormack, D. (2001). Models and simulations for learning in complex domains: using causal loop diagrams for assessment and evaluation. Computers in Human Behavior, 17, 517-545. doi: 10.1016/S0747-5632(01)00025-5

Sudatha, I., Degeng, I., \& Kamdi, W. (2018). The effect of visualization type and student spatial abilities on learning achievement. Journal of Baltic Science Education, 17, 551-563.

Sweller, J. (1994). Cognitive load theory, learning difficulty, and instructional design. Learning and Instruction, 4, 295-312. doi: 10.1016/0959-4752(94)90003-5 
Sweller, J. (2005). Implications of cognitive load theory for multimedia learning. In R. E. Mayer (Ed.), The Cambridge handbook of multimedia learning (pp. 19-30). New York, NY: Cambridge University Press.

Sweller, J., \& Chandler, P. (1994). Why some material is difficult to learn. Cognition and Instruction, 12, 185233. doi: 10.1207/s1532690xci1203_1

Sweller, J., Ayers, P., Kalyuga, S. (2011). Cognitive load theory. Springer, New York.

Sweller, J., Van Merriënboer, J. J. G., \& Paas, F. (1998). Cognitive architecture and instructional design. Educational Psychology Review, 10, 251-296. doi: 10.1207/s1532690xci1203_1

Swezey, R. W. (1991). Effects of instructional strategy and motion presentation conditions on the acquisition and transfer of electromechanical troubleshooting skill. Human Factors, 33, 309-323. doi: $10.1177 / 001872089103300306$

Tversky, B., Heiser, J., Mackenzie, R., Lozano, S., \& Morrison, J. (2008). Enriching animations. In R. K. Lowe, \& W. Schnotz (Eds.), Learning with animation: Research implications for design (pp. 263-285). New York: Cambridge University Press.

Tversky, B., Morrison, J. B., \& Bétrancourt, M. (2002). Animation: Can it facilitate? International Journal of Human Computer Studies, 57, 247-262. doi: 10.1006/ijhc.1017

Ülen, S., Čagran, B., Slavinec, M., \& Gerlič, I. (2014). Designing and evaluating the effectiveness of Physletbased learning materials in supporting conceptual learning in secondary school physics. Journal of Science Education and Technology, 23, 658-667. doi: 10.1007/s10956-014-9492-x

Ülen, S., Gerlič, I., Slavinec, M., \& Repnik, R. (2017). Evaluating the Effectiveness of Physlet-Based Materials in Supporting Conceptual Learning About Electricity. Journal of Science Education and Technology, 26,151-160. doi: 10.1007/s10956-016-9661-1

Van Merriënboer, J. J. G., \& Kirschner, P. A. (2007). Ten steps to complex learning. Mahwah, NJ: Lawrence Erlbaum.

Van Merriënboer, J. J. G., \& Sweller, J. (2005). Cognitive load theory and complex learning: Recent developments and future directions. Educational Psychology Review, 17, 147-177. doi: 10.1007/s10648005-3951-0

Van Merriënboer, J. J. G., Kester, L. \& Paas, F. (2006). Teaching complex rather than simple tasks: Balancing intrinsic and germane load to enhance transfer of learning. Applied Cognitive Psychology, 20, 343-352. doi: $10.1002 /$ acp. 1250

Viennot, L. (2003). Teaching physics. Dodrecht: Kluwer.

Zacks, J., Tversky, B., \& Iyer, G. (2001). Perceiving, remembering, and communicating structure in events. Journal of Experimental Psychology: General, 130, 29-58. doi: 10.1037/0096-3445.130.1.29

Zukić, M. Đapo, N., \& Husremović Dž. (2016). Construct and Predictive Validity of an Instrument for Measuring Intrinsic, Extraneous and Germane Cognitive Load. Universal Journal of Psychology, 4, 242248.

\section{Author Information}

Dževdeta Dervić
Second Gymnasium Sarajevo
Sutjeska 1, 71000 Sarajevo,
Bosnia and Herzegovina
Contact e-mail: dzevdeta.dervic@2gimnazija.edu.ba

\section{Vanes Mešić}

Faculty of Natural Sciences

Zmaja od Bosne 35, 71000 Sarajevo, Bosnia and Herzegovina

\author{
Nermin Đapo \\ Faculty of Philosophy, University of Sarajevo \\ Franje Račkog, 71000 Sarajevo, \\ Bosnia and Herzegovina
}

\section{Ratko Đokić}

Faculty of Philosophy, University of Sarajevo Franje Račkog, 71000 Sarajevo, Bosnia and Herzegovina 